\title{
Evaluation and Comparative Study on the Influence of WeChat Official Accounts of Jiangsu Smart Scenic Spots Based on the Data of 5A Scenic Spots
}

\author{
Jialin Yuan ${ }^{1}$, Zhijun Yan ${ }^{1}$ and Jun Wen ${ }^{1,2, *}$ \\ ${ }^{1}$ School of Economics and Management, Nanjing University of Science \& Technology, Nanjing, Jiangsu 210094, China \\ ${ }^{2}$ Research Centre of Saudi Arabia, Nanjing University of Science \& Technology, Nanjing, Jiangsu 210094, China \\ *Corresponding author. Email: njustwen@126.com
}

\begin{abstract}
The purpose of the paper is to study the influence of WeChat official accounts of scenic spots under the background of smart tourism, so that we can help scenic spots know the existing problems in marketing and improve their online marketing methods. The extant kinds of literature rarely involve the influence of touristic WeChat accounts. Therefore, this paper chose 24 A smart scenic spots' WeChat official accounts and made a comparative study of them to analyze the influence. We collected the data on $245 \mathrm{~A}$ smart scenic spots in Jiangsu province and evaluated and ranked their influence based on factor analysis. It is found that WeChat official accounts of 24 scenic spots display uneven influence and their gap is clear-cut.
\end{abstract}

Keywords: Smart tourism; Factor analysis; WeChat official account; 5 A scenic spots

\section{INTRODUCTION}

The concept of smart tourism was first coined by Zhenjiang, one of the cities in Jiangsu province in 2010. It is defined as a new type of tourism with the utilization of the internet and telecommunication technology[1].

With the emergence of smart tourism, smart tourism marketing came into being. It is to combine the marketing of tourism products with big data network and make full use of emerging technologies so that it serves enterprises and consumers more quickly. With the rapid development of self-media, WeChat official accounts have increasingly become one of the popular marketing methods. Tourism is information-intensive. The timely dissemination of tourism information is very important, which coincides with the function of WeChat official account.

Therefore, the purpose of this paper is to study the influence of WeChat official accounts in scenic spots and make a comparative study. It can help different scenic spots improve their marketing methods and know about their advantages and weaknesses of smart marketing, so as to enhance their influence and promote the development of smart tourism.

\section{RELATED LITERATURE}

With the emergence of WeChat media, WeChat users are growing, and WeChat account has quickly become an important media for the public to source information and increase publicity. Shen Yanni[2] claims that WeChat account, as a new medium, has a far-reaching influence on hospital publicity. Yang Ying[3] found that WeChat account has become an important platform for universities to publicize and cultivate talents by studying the influence of official WeChat in universities.

In the aspect of touristic WeChat account, Qu Yanan[4] found that the influence pattern of WeChat accounts in the scenic spots is spatially aggregated by studying the $5 \mathrm{~A}$ scenic spots in Xinjiang, and the popularity and publicity of scenic spots have an obvious impact on WeChat account.

The extant studies on the influence of WeChat accounts are widely covered, involving many fields, but they're scarce literature on the influence of touristic WeChat accounts. Therefore, this paper will take 5A scenic WeChat accounts in Jiangsu Province as research samples and analyze their influence and make a comparison based on factor analysis. Finally, it provides useful implications for smart touristic marketing of scenic spots in Jiangsu Province and even the whole country.

\section{MEASUREMENT OF INFLUENCE OF SCENIC SPOTS}

Considering that it is too weak to measure the influence of a WeChat account only by the number of fans, the indicators of measuring the influence of WeChat accounts should be comprehensively considered from all aspects. Concerning the literature, it is found that the construction and research on the evaluation indices of the influence of public media are well documented.

Shen Hui[5] proposes that in the process of studying new media, the influence of the subject can be determined by the number of fans, the ability of information dissemination and the interaction behavior with 
individuals. The influence in the process of new media operation can be measured by the number of articles published, the content published being praised, read and commented on by others. Zhang Liang and Zhang Rilong[6] evaluate and analyze the communication power of WeChat accounts based on factor analysis. They select constructs such as total reading number, average reading number and average published articles, etc., revealing the correlation among evaluation indicators, and analyzing the influencing factors of the correlation. Chen $\mathrm{Xu}$ [7] and others put forward the Personal Rank algorithm based on the Rage Rank algorithm model, which analyzes the influence of users, and takes the index of forwarding number and fan number into consideration, and finds that there is a weak correlation between them.

To sum up, this paper constructs a measurement framework (shown in Table 1). It is classified into three first-order constructs, namely, WeChat account coverage, user activity and interactivity. Under the first-order constructs, there are seven sub-constructs, i.e., the number of active fans, the total number of articles posted, the average number of articles per day, the average number of articles per day during the assessment period, the average page views during the assessment period, the average number of likes per article during the assessment period and the average number of views per article during the assessment period.

Table 1. Measurement Framework of WeChat account's influence of scenic spots

\begin{tabular}{|c|c|}
\hline $\begin{array}{l}\text { First-order } \\
\text { Constructs }\end{array}$ & Second-order Constructs \\
\hline \multirow{2}{*}{$\begin{array}{l}\text { WeChat account } \\
\text { coverage }(\mathrm{A})\end{array}$} & the number of active fans(A1) \\
\hline & $\begin{array}{c}\text { total number of articles } \\
\text { published(A2) }\end{array}$ \\
\hline \multirow[b]{2}{*}{ User activity(B) } & $\begin{array}{l}\text { the average number of articles per } \\
\text { day(B1) }\end{array}$ \\
\hline & $\begin{array}{c}\text { the average number of articles per } \\
\text { day during the evaluation } \\
\text { period(B2) }\end{array}$ \\
\hline \multirow{3}{*}{$\operatorname{Interactivity}(\mathrm{C})$} & $\begin{array}{l}\text { average page views during the } \\
\text { evaluation period }(\mathrm{C} 1)\end{array}$ \\
\hline & $\begin{array}{l}\text { the average number of likes per } \\
\text { article during the evaluation } \\
\text { period }(\mathrm{C} 2)\end{array}$ \\
\hline & $\begin{array}{l}\text { the average number of views per } \\
\text { article during the evaluation } \\
\text { period(C3) }\end{array}$ \\
\hline
\end{tabular}

\section{RESULTS AND DISCUSSIONS}

\subsection{Data Sources}

Jiangsu Province is rich in touristic resources in China. As of December 2020, there are 24 5A-level scenic spots in
Jiangsu Province. It plays an important role in national tourism. Zhenjiang, a city in Jiangsu Province, took the lead in coining the concept of smart tourism in 2010. It can be seen that the development of smart tourism in Jiangsu Province has a good foundation and driving force. Therefore, this paper chooses $5 \mathrm{~A}$ scenic spots in Jiangsu Province to study the influence of smart scenic spots' WeChat accounts. After investigation, all the $245 \mathrm{~A}$ scenic spots in Jiangsu have opened WeChat accounts. The earliest is China Dinosaur Park, which opened on November 15, 2012, and the latest is Zhongshi Communication Wuxi Movie and Television Base, which opened on December 24, 2019. We selected December 6, 2020 to December 15, 2020 as our sample period. All the data come from scenic WeChat official account and Qingbo Data Network.

\subsection{Factor Analysis}

The method of factor analysis is used with the help of SPSS software. After finding out the common factors of the above seven constructs, building up the comprehensive evaluation function according to the weight. Then, according to the newly obtained evaluation function, we calculated the comprehensive score of WeChat official account's influence, and then sorted for discussion.

\subsubsection{KMO and Bartlett Test}

Table 2. KMO and Bartlett's Test

\begin{tabular}{|c|c|c|}
\hline \multicolumn{2}{|l|}{ Kaiser-Meyer-Olkin Measure of } & 0.540 \\
Sampling Adequacy. & \\
\hline \multirow{2}{*}{$\begin{array}{c}\text { Bartlett's Test } \\
\text { of Sphericity }\end{array}$} & Approx. Chi-Square & 284.727 \\
\cline { 2 - 3 } & df & 21 \\
\cline { 2 - 3 } & Sig. & 0.000 \\
\hline
\end{tabular}

According to Table 2, the KMO is 0.540, and the Bartlett spherical test results show that the significance test result of the sample index is 0.000 . Kaiser[8] points out that the original variable is suitable for factor analysis when KMO is greater than 0.5 and the significance level is less than 0.005. Therefore, this result falls within the range suitable for factor analysis.

\subsubsection{Explanatory Factor Analysis}

According to the result, the eigenvalues of the first two factors are 3.350 and 2.300 respectively and both of them are above 1 . The variance contribution rates are $47.862 \%$ and $32.853 \%$, respectively, and the cumulative contribution rate is $80.715 \%$, exceeding $80 \%$. After analysis, we can extract the first two factors as the main factors to represent all indicators in the evaluation system. 


\subsubsection{Interpretation and Naming of Factors}

The maximum variance orthogonal research method is adopted to solve the naming problem of factors[9].

It can be seen in Table 3 from the rotated factor load matrix that factor 1 mainly carries the number of active fans (A1), average page views during the evaluation period(C1), the average number of likes per article during the evaluation period(C2) and the average number of views per article during the evaluation period $(\mathrm{C} 3)$. These indicators reflect the connection and interaction between WeChat official account and its audience, so factor 1 is named as the principal component of interactive feedback. Factor 2 mainly carries a total number of articles published (A2), the average number of articles per day (B1) and the average number of articles per day during the evaluation period (B2). These indicators reflect the activity degree of WeChat official account itself, so factor 2 is named as the principal component of user activity.

Table 3. Rotated Component Matrix

\begin{tabular}{|c|c|c|}
\hline & \multicolumn{2}{|c|}{ Component } \\
\cline { 2 - 3 } & 1 & 2 \\
\hline A1 & 0.300 & 0.006 \\
\hline A2 & -0.101 & 0.942 \\
\hline B1 & -0.082 & 0.955 \\
\hline B2 & -0.021 & 0.901 \\
\hline C1 & 0.990 & -0.093 \\
\hline C2 & 0.978 & -0.107 \\
\hline C3 & 0.982 & -0.107 \\
\hline
\end{tabular}

\subsubsection{Factor Score Coefficient Matrix}

According to the factor principal component score coefficient matrix, the formulas can be obtained:

$\mathrm{F} 1=0.103 * \mathrm{~A} 1+0.026 * \mathrm{~A} 2+0.033 * \mathrm{~B} 1+0.050 * \mathrm{~B} 2+0.334 * \mathrm{C} 1$ $+0.329 * \mathrm{C} 2+0.330 * \mathrm{C} 3$
$\mathrm{F} 2=0.022 * \mathrm{~A} 1+0.361 * \mathrm{~A} 2+0.368 * \mathrm{~B} 1+0.350 * \mathrm{~B} 2+0.027 * \mathrm{C} 1$ $+0.021 * \mathrm{C} 2+0.021 * \mathrm{C} 3$

$\mathrm{F}=(0.42968 * \mathrm{~F} 1+0.37747 * \mathrm{~F} 2) / 0.80715$

After calculation, we got the principal component score and a comprehensive score of the official WeChat accounts of 24 5A-level tourist attractions in Jiangsu Province as shown in Table 4.

Table 4. Principal component score and comprehensive score

\begin{tabular}{|c|c|c|c|}
\hline Name & F1 Score & F2 Score & F Score \\
\hline Zhongshan Scenic Spot & 4.519 & -0.541 & 2.14 \\
\hline Suzhou Taihu National Tourism Vacation Zone & -0.019 & 2.392 & 1.07 \\
\hline Tongli Travel & -0.151 & 2.102 & 0.90 \\
\hline Shajiabang Tourism & -0.192 & 1.643 & 0.67 \\
\hline Wuxi Lingshan Scenic Spot & 0.167 & 1.119 & 0.61 \\
\hline China Dinosaur Park & -0.053 & 0.778 & 0.34 \\
\hline Suzhou Garden Tourism & 0.459 & -0.070 & 0.21 \\
\hline Huaguoshan Scenic Area & -0.225 & 0.344 & 0.04 \\
\hline Yuantouzhu Scenic Area & -0.010 & 0.072 & 0.03 \\
\hline Slender West Lake & 0.053 & -0.036 & 0.01 \\
\hline Jurong Maoshan Scenic Area & -0.311 & 0.219 & -0.06 \\
\hline Love in Jinji Lake & -0.255 & 0.152 & -0.06 \\
\hline Huishan Ancient Town Scenic Spot & -0.170 & 0.152 & -0.06 \\
\hline Zhouenlai Hometown Scenic Spot & -0.313 & 0.161 & -0.09 \\
\hline Tianmu Lake & 0.227 & -0.487 & -0.11 \\
\hline Zhouzhuang Travel & 0.168 & -0.464 & -0.13 \\
\hline Qinhu Tourism Scenic Spot & -0.434 & -0.530 & -0.48 \\
\hline Nanjing Confucius Temple & -0.369 & -0.761 & -0.55 \\
\hline Chinese Chunqiuyancheng Tourism Area & -0.473 & -0.676 & -0.57 \\
\hline Xuzhou Yunlong Lake Tourist Area & -0.480 & -0.812 & -0.63 \\
\hline Zhongshi Communication Wuxi Movie and Television Base & -0.469 & -1.112 & -0.77 \\
\hline China Elk Garden & -0.534 & -1.147 & -0.82 \\
\hline Zhenjiang Beigu Mountain Scenic Spot & -0.523 & -1.190 & -0.83 \\
\hline Nantong Hao River Travel & -0.539 & -1.179 & -0.84 \\
\hline
\end{tabular}




\section{CONCLUSION AND IMPLICATIONS}

\subsection{Conclusion}

From the score of factor 1 , that is, interactive feedback factor, it can be seen that Zhongshan Scenic Area, Suzhou Garden Tourism, Tianmu Lake, Zhouzhuang Travel and Wuxi Lingshan Scenic Spot rank in the top five. The WeChat account in these five scenic spots has more interactions with the audience. The articles are widely concerned and the audience has more feedback.

From the score of factor 2, that is, user activity factor, it can be seen that Suzhou Taihu National Tourism Vacation Zone, Tongli Travel, Shajiabang Tourism, Wuxi Lingshan Scenic Spot and China Dinosaur Park rank in the top five. The WeChat accounts in these five scenic spots are highly active and frequently posts articles.

According to the comprehensive scores, Zhongshan Scenic Area, Suzhou Taihu National Tourism Vacation Zone, Tongli Travel, Shajiabang Tourism and Wuxi Lingshan Scenic Spot rank top five out of 24 scenic spots. China Elk Garden, Zhenjiang Beigu Mountain Scenic Spot and Nantong Hao River Travel rank bottom three.

Zhongshan Scenic Area ranks the first mainly because Zhongshan Scenic Area itself has high popularity. It has a superior geographical position. Furthermore, the interactive feedback degree of fans is high as well as the frequency of posting activities.

China Elk Garden, Zhenjiang Beigu Mountain Scenic Spot and Nantong Hao River Travel are the bottom three in terms of interactive feedback factor and user activity factor. They do not have enough popularity. These three scenic spots are located in Yancheng, Zhenjiang and Nantong respectively. So that they don't have advantages in geographical location. Finally, the users show a low degree of participation and interactive activities. In addition, the posts are boring and unattractive.

\subsection{Implications}

There are some implications to improve the influence. Firstly, they should increase the activities of scenic WeChat official accounts and encourage tourists to become fans of the WeChat official accounts, so as to enhance its influence. Secondly, they should increase the interactive content with fans. They are able to publicize some activities to attract tourists. Thirdly, they should keep up with social focus and tide. Social hot issues and fashion have always been the focus of public attention. Zhongshan Scenic Area published an article entitled "@ Ding Zhen, here is your dream, your world!" It is close to current events and attracts readers, resulting in 35,000 page views.

\section{ACKNOWLEDGMENT}

The paper is financially supported by Jiangsu Provincial Department of Culture and Tourism (Grant no. 20YB27) and Jiangsu Social Science Fund Project (No. 17JYB001).

\section{REFERENCES}

[1] Zong Ziyi. The Promotion of Smart Tourism on Smart Scenic Spots Marketing-Taking Smart Summer Palace As an Example [J]. Modern Vocational Education, 2020(42):134-135. (In Chinese)

[2] Shen Yanni. The Importance and Application Strategy of WeChat Official Account in Hospital Publicity [J]. Western Radio and Television, 2020,41(24):98-100. (In Chinese)

[3] Yangying, Xie Yuanyuan and Li Yuxiao. The Impact Evaluation and Empirical Study of the WeChat Official Account of Universities [J]. Journal of Hefei University of Technology (Social Science Edition), 2020, 34(06):119-124. (In Chinese)

[4] Qu Yanan and Liang Xiao. Study on the Influence and Audience Preference of Touristic WeChat Official Account-A Case Study of 5A Scenic Spots in Xinjiang [J]. Journal of Xinjiang Finance \& Economics Institute, 2018(04):46-54. (In Chinese)

[5] Shen Hui. Research and Implementation of a User Influence Measurement Method Based on Weibo [D]. Yanshan University, 2015. (In Chinese)

[6] Zhang Liang, Zhang Rilong. Study on the Evaluation Index System of the Communication Power of WeChat Official Account. [J]. New Media Research, 2019,5(22):1-7. (In Chinese)

[7] Chen Xu, Wang Pengfei, Qin Zheng, et al. HLBPR: a hybrid local bayesian personal ranking method[C]// Proc of International Conference Companion on World Wide Web. International World Wide Web Conferences Steering Committee, 2016: 21-22.

[8] Kaiser, H.F.1970. A Second Generation Little Jiffy. Psychometrika, 35(4):401-415

[9] Hu Yuzhen. Enterprise Financial Performance Research Based on Factor Analysis [J]. Marketing Research, 2020(03):59-61. (In Chinese) 